\title{
Docência e práticas catalisadoras: possibilidades entre as influências das mídias digitais e valores humano-sociais
}

\author{
Teaching and catalyzing practices: possibilities among the influences of \\ digital cultures and human social values
}

\author{
Enseñanza y prácticas catalizadoras: entre las influencias de los \\ medios digitales y los valores humano-sociales
}

\author{
Regina CELY DE CAMPos HagemeYeR* \\ Cleusa VAlÉRIO Gabardo**
}

\begin{abstract}
RESUMO - Apresenta-se neste artigo a pesquisa sobre um grupo representativo de seis professores de escolas públicas de Curitiba, definidos por Hagemeyer como professores catalisadores que compreendem e identificam os novos valores gerados pela cultura das mídias digitais em estudantes da escola atual, objetivando identificar novas lógicas e possibilidades presentes nas referidas práticas. Situa-se o lugar de onde falam os professores, no panorama pós-moderno de mudanças contemporâneas que interferem na docência e nos cursos de Pedagogia, com base em Costa, Hall e Giroux, para retomar os conceitos de sujeito, subjetividade e ética, com apoio teórico de Foucault e Guattari. Foram identificados, nas práticas pesquisadas, referenciais que resgatam os valores dos estudantes, articulando-os a valores humano-sociais. Tais reflexões apontam aos cursos de formação docente uma ampliação de estudos e pesquisas sobre o trato dos valores das culturas jovens que decorrem das mídias digitais.
\end{abstract}

Palavras-chave - Docência. Práticas catalisadoras. Valores humano-sociais.

\begin{abstract}
In this article, it is introduced a research about a representative group of six teachers of public schools in Curitiba, defined by Hagemeyer, as catalyzing teachers, that understands the new interests and values generated by the culture of digital media in students of the present day school, seeking to identify the tendencies, new logics and possibilities that are present in their practice. It establishes the position from which teachers speak, in the panorama of contemporary changes that interfere in teaching and in Pedagogy courses, based in Costa, Hall and Giroux. In order, to reassume the concepts of subject, subjectivity and ethics. The qualitative research was based in Shulman and the analysis was supported by Foucault and Guattari, and has identified in the teaching practice, strategies referential that recover the values of the students, articulating them with the human social values. Such reflections demand from courses of teachers formation, analysis about the processes of digital media in the youth cultures.
\end{abstract}

Keywords - Teaching. Catalyzing practices. Human social values.

RESUMEN - Presentamos en este trabajo, la investigación sobre un grupo representativo de seis maestros de escuelas públicas de Curitiba, definidos por Hagemeyer, como profesores catalizadores, que comprenden y identifican los nuevos valores generados por la cultura de los medios digitales a los estudiantes en la escuela actual, para identificar nuevas lógicas y posibilidades presentes en estas prácticas. Se sitúa el lugar de donde los maestros hablan, en el panorama de los cambios contemporáneos que interfieren en la enseñanza y en los cursos de Pedagogía, utilizando como base utilizando como base, Costa, Hall y Giroux para reanudar en este escenario, los conceptos de sujeto, la subjetividad y la ética, con el apoyo teórico de Foucault e Guattari. Fueron identificados en las prácticas investigadas, puntos de referencia que redimen a los valores de los alumnos, creando vinculación a los valores humanos-sociales. Tales reflexiones requieren a los cursos de formación del profesorado, una extensión de los estudios y la investigación sobre el tratamiento de los valores de las culturas juveniles que se derivan de los medios de comunicación digitales. Palabras-clave - Enseñanza. Prácticas catalizadoras. Valores humano-sociales.

\footnotetext{
*Doutora em Educação pela Universidade de São Paulo (São Paulo, SP, Brasil) e Professora na Universidade Federal do Paraná (Curitiba, Paraná, Brasil). E-mail: <regicely@terra.com.br>.

**Doutora em Educação pela Universidade de Salamanca (Salamanca, Espanha) e Professora na Universidade Federal do Paraná (Curitiba, Paraná, Brasil). E-mail: <cleusavalerio@yahoo.com.br>.
} 


\section{INTRODUÇÃO}

Nos últimos anos, presencia-se a evolução das tecnologias e a constante intensificação dos usos dos instrumentos de comunicação, informação e entretenimento, com grande impacto nos interesses e valores de adolescentes e jovens da escola contemporânea. Interpelados por novas lógicas e significados decorrentes da cultura das mídias digitais, ${ }^{1}$ grupos de professores preocupam-se em como transitar entre as novas formas de ser, estar e se relacionar dos estudantes no âmbito escolar e procuram rever concepções, atitudes e estratégias no trato de suas identidades e valores.

$\mathrm{Na}$ presente abordagem, propõe-se analisar as investigações realizadas com a participação de seis professores de escolas públicas de Curitiba, levadas a efeito por pesquisadoras bolsistas de Iniciação Científica, no período de 2009 a 2013. ${ }^{2}$ Esses professores, definidos por Hagemeyer (2006) como catalisadores, assimilam e compreendem os valores dos estudantes da escola contemporânea, gerados pelas mídias digitais, e, ao problematizá-los, buscam novas possibilidades de tratar as identidades e os valores dos estudantes. Os professores foram selecionados pela característica catalisadora de suas práticas e indicados em banco de dados da coordenação do Projeto (autoras deste artigo) em contato com equipes pedagógicas das escolas e em pesquisa nos sites ou portais de educação e de escolas públicas.

As pesquisas sobre professores que desenvolvem práticas que se diferenciam diante das mudanças contextuais contemporâneas tiveram início em 2001 e culminaram com trabalho de tese de doutorado, em 2006, ${ }^{3}$ de Hagemeyer (2006). Na investigação buscou-se identificar o que leva grupos de professores a desenvolver uma atuação que se diferencia nas escolas e cuja qualidade diz respeito às novas conformações culturais dos estudantes.

$\mathrm{Na}$ investigação foram considerados quatro campos de formação e atuação desses professores: o profissional, o do conhecimento científico, o didático pedagógico e o humano-social. Este último emergiu das reiteradas preocupações externadas pelos professores pesquisados em 2004 sobre as influências das mídias digitais e de entretenimento nas identidades e valores dos estudantes, levando-os a discutir valores éticos, de direitos humanos e de igualdade social, entre outros, que foram definidos como humano-sociais, tema que constitui o foco da pesquisa ora proposta.

Propõe-se, portanto, investigar as formas como os professores catalisadores têm tratado os valores dos estudantes da escola pública atual diante dos interesses gerados pela cultura das mídias digitais, para analisar e identificar as possibilidades de novas lógicas, atitudes e estratégias, considerando valores humano-sociais (éticos, de direitos humanos e de igualdade social entre outros).

Optou-se pela pesquisa qualitativa, realizada com base em Lüdke e André (1986) e referenciais considerados por Lee Shulman (1986), autor que desde 1990 investigou os processos que os professores desenvolvem ao ensinar. Buscou-se considerar a compreensão que os professores revelam sobre os conhecimentos e valores dos estudantes e a verbalização dos professores sobre os movimentos de suas práticas, entre as influências das mídias digitais e o trabalho de valores humano-sociais.

Para situar o lugar de onde falam os professores pesquisados, contextualizam-se brevemente os processos de mudança da sociedade contemporânea, situando as questões que influenciam a formação e as práticas dos professores entre os processos da modernidade e da pósmodernidade, considerando as contribuições dos estudos culturais como possibilidade que amplia leituras sobre as culturas jovens, com base em Costa (2010), Giroux (1993; 1999), Hall (1997) e Bauman (2001). Essa discussão levou à retomada de conceitos fundamentais que circundam a cultura e os processos da formação humana no panorama contemporâneo, notadamente as noções de sujeito, subjetividade, identidade e ética, com base nas teorizações de Foucault (1999; 2004) e Guattari (1987), para identificar elementos de análise a serem considerados na pesquisa proposta.

Os questionamentos de convicções verbalizadas sobre os significados que permeiam a cultura dos estudantes na era da cultura digital expressam as formas como os professores catalisadores priorizaram atividades e atitudes em função dos valores dos estudantes e de novas lógicas em suas relações e objetivos de vida. Nas análises, propõe-se identificar referenciais das práticas dos professores pesquisados que contribuam para novas possibilidades de trato dos processos valorativos das culturas de adolescentes e jovens estudantes, gerados pelas mídias digitais na escola atual, contribuindo com a ampliação dessas discussões nos cursos de Pedagogia e demais licenciaturas que formam professores.

\section{O LUGAR DE ONDE FALAM OS PROFESSORES - NECESSIDADES E TENSÕES DA ATUAÇÃO DOCENTE NO CONTEXTO CONTEMPORÂNEO E AS MUDANÇAS CULTURAIS: CONCEPÇÕES DA PÓS-MODERNIDADE}

Analisar as práticas dos professores como participantes e protagonistas das mudanças sociais implica situar o lugar de onde falam, entre a modernidade, cujos estatutos da racionalidade técnica foram formados, e a pós-modernidade, ${ }^{4}$ como processo de mudanças históricas e de transformações culturais que interferem 
nos processos educacionais escolares e no trabalho dos professores.

Entre os pensadores que caracterizaram as concepções filosóficas da pós-modernidade, Giroux (1993) estabeleceu comparações entre as posições de vários autores, e nesta abordagem propõe-se considerar, de forma breve, as posições de dois deles que se tornaram fundamentais nas análises das influências das mídias digitais nas transformações contemporâneas: Jean François Lyotard (1998) e Frederic Jameson (1996). O primeiro rejeita as grandes narrativas e as visões totalizantes, considerando que a pós-modernidade está articulada às condições de evolução científica e tecnológica, cujas inovações conduzem à criação de condições novas e inusitadas, geradas nas sociedades ocidentais pelo conhecimento científico, pela tecnologia avançada e por textos eletrônicos, em meio aos quais os indivíduos tendem a traçar o seu próprio caminho sem o auxílio de referentes fixos ou arrimos filosóficos.

Jameson (1996) não rompe com as grandes narrativas e em suas posições interpreta a pós-modernidade como "a lógica cultural do capital”, e não como uma condição póshistórica. Aponta para a emergência dos desenvolvimentos tecnológicos na sociedade capitalista, que conformam novos mapas cognitivos, os quais demandam formas de representação para uma leitura sistemática dos significados de uma nova era.

Nas visões desses autores, que se diferenciam ideologicamente, percebe-se que há, no entanto, uma concordância sobre a força das influências da evolução tecnológica e das mídias digitais nas sociedades ocidentais que interferem na reorganização das formas econômicas capitalistas, a caminho da globalização. Apontam os processos dominantes e massificadores gerados pela intensificação dessas mídias que incidem sobre a formação dos sujeitos sociais, o que demanda dos educadores e professores discussões e revisões sobre a formação de identidades e valores na educação escolar contemporânea.

Para auxiliar nas análises da pesquisa proposta, caracterizam-se as tendências que influenciam as novas leituras sobre os processos culturais da sociedade contemporânea e seus movimentos teóricos. No final do século XX e início do século XXI, essas concepções têm sido compartilhadas por autores que se aproximam das visões pós-modernas, dentre as quais se destaca a expressão definida como virada linguística. Para Costa (2010, p. 133), "as sociedades e culturas atuais são dirigidas por poderosas ordens discursivas que regem o que deve ser dito e o que deve ser calado, incluindo os sujeitos sociais". Nessa perspectiva, a "realidade" tornou-se o resultado de um processo que, como toda forma de expressão, tem um papel no qual a narrativa $e$ os textos descrevem ou falam sobre as coisas, inventando subjetividades.

Em conformidade com as visões de Foucault (1999), Costa (2010) afirma que nesses processos há implicações de poder, não um poder maligno, dissimulado, que emana de uma única fonte, mas um poder produtivo, disseminado, que se exerce na forma de "uma vontade de saber" e de "poder" e que compõe um domínio sobre os discursos que circulam na sociedade, subjetivando identidades.

De outra perspectiva, a cultura passou a constituir um papel definitivo de análise dos processos de mudança contemporâneos e integra o campo epistemológico, que Stuart Hall (1997) definiu como virada cultural, a qual se expressou em um corpo teórico definido como estudos culturais. Esses estudos constituem um campo fecundo de análise centrada nas pedagogias culturais que constituem os sujeitos, na composição de identidades e na disseminação de práticas e condutas, que delineiam as formas de viver e ser na sociedade contemporânea, notadamente a partir da cultura das mídias digitais.

$\mathrm{Na}$ presente abordagem, discutem-se as práticas dos professores catalisadores, considerando que na escola contemporânea tornam-se agentes culturais que, em suas compreensões e atividades, expressam uma nova qualidade do trabalho docente, de interpretação de significados e códigos das mídias digitais, que configuram os valores dos jovens estudantes, possibilitando a busca de novas lógicas e estratégias pedagógicas ao tratar suas identidades e valores.

Costa (2010) cita Giroux (1999), ${ }^{5}$ que tem apresentado revisões sobre as concepções da condução do trabalho educacional docente na sociedade contemporânea e discute a tradição conservadora dos cursos de Pedagogia, voltados somente aos processos de transmissão dos conteúdos das disciplinas escolares, associados aos valores dominantes nesta sociedade. Refere-se à busca de uma abordagem mais ampla e plurifacetada dos cursos de Pedagogia que contemple as interfaces entre a educação, a escola e a cultura.

Sob essa perspectiva, situa-se a inserção dos elementos aportados por Hagemeyer (2006) para uma análise que considere o avanço das compreensões dos professores sobre os sujeitos da escola pública atual e sobre o contexto em que se inserem. Lee Shulman (1986), autor que desde 1990 analisa os processos de ensino que os professores desenvolvem, mobilizando conhecimentos aliados ao contexto em que atuam, qualifica esse processo como uma forma de "amalgamar" esses conhecimentos nos propósitos de ensinar e de formar valores.

Para identificar os elementos de análise decorrentes dos processos sociais e culturais relativos aos processos de formação dos estudantes da escola atual, retomam-se a seguir as noções de sujeito, subjetividade, identidade 
e ética, para identificar novos temas e problemas que passam a ter significado nas discussões sobre o trato dos valores.

\section{REFLEXÕES SOBRE SUJEITOS, SUBJETIVIDADE E ÉTICA NA SOCIEDADE E NA ESCOLA CONTEMPORÂNEA}

Diante das transformações das manifestações culturais contemporâneas, Costa (2006) chama a atenção para a ambiguidade que circunda os significados atribuídos à ideia de sujeito, antes concebida como ideia de indivíduo centrado, estável e do qual emanaria um sentido identitário e autônomo. Para Hall (1997), na sociedade atual os indivíduos, ou sujeitos, encontram-se deslocados do seu lugar no mundo e de si mesmos, o que define uma "crise de identidade".

Como qualifica Bauman (2001), por se estar vivendo em uma era na qual tudo que se tinha como certo pode mudar de forma a qualquer momento, há um caráter volátil, provisório e instável nos domínios da vida contemporânea que incide sobre as concepções de segurança e medo dos indivíduos, como também de identidade, amor e da ética, que integram as escolhas dos sujeitos sociais.

Green e Bigun (2005), na emergência do que identificam como sujeito estudante pós-moderno, alertam para a "categoria da juventude", a qual analisa as mudanças das culturas jovens na sociedade contemporânea. Referem-se à velocidade e à capacidade de fazer mais coisas de forma rápida e aos domínios dos recursos da computação e do mundo virtual na vida dos jovens, revelando uma união entre a máquina e o ser humano de forma cada vez mais "natural".

Para Momo e Costa (2009), há uma infância/adolescência pós-moderna na escola, de estudantes que se constituem a partir dos apelos do consumo de artefatos em voga na mídia no momento, e que muda constantemente, e tornam-se o que são, vivendo sob a condição pósmoderna.

Para Ramos do Ó e Costa (2007), as linguagens que se expressam hoje, decorrentes das novas tecnologias, viabilizam complexos jogos, sendo a identidade pessoal uma construção inacabada, e o eu um "projeto marcado por múltiplas trajetórias", no qual o aparato discursivo que comporta produz subjetividades. Esses novos jeitos de "ser sujeito", novas formas de "ser pessoa humana", produzem a homogeneidade e a normalização, que também podem levar a estigmatizações sobre "ser inteligente", ou "não ser bonito", ou "autocontrolado", como formas de garantir "sucesso".

Ao problematizar os modos de sujeição impostos na sociedade globalizada, Foucault (2004) referiu-se ao novo modo de ser sujeito na sociedade capitalista, sob as imposições de verdades e condutas morais, do ponto de vista da manutenção de processos sociais gerados nessa sociedade e que se tornaram um modo de produzir os sujeitos sociais, definidos pelo autor como um processo de subjetivação.

Bondía (2002) questiona o papel da educação formal, que naturaliza na prática cotidiana a "elevação de si" e a "desqualificação do outro", como se observa nos processos sociais na sociedade globalizada. Essa forma de agir tem se tornado presente também nas novelas, programações televisivas, propagandas e na pedagogia escolar.

Fisher (2005) alerta sobre o olhar "do que falta no outro" como característica do discurso pedagógico, que elabora seus projetos a partir do que está incompleto nos jovens. Na formação da subjetividade, este é um procedimento que descarta a diferença e estabelece padrões de normalidade, por vezes intransponíveis para os adolescentes. Em face da exigência de padrões de normalidade promovidos pela mídia televisiva, há uma construção da qual não se fala e na qual crianças, adolescentes e jovens sofrem forte vigilância e que tende também a desqualificar suas opiniões e identidades.

Compreender os processos de subjetivação expressos nos interesses e valores dos estudantes, também conformados nos espaços das mídias e suas programações, tem levado os professores a reconsiderar as formas de poder disciplinar nas instituições educacionais. Foucault (1999) volta-se contra as regras de obediência de forma explícita e/ou simbólica, questionando a dualidade da relação saber/poder, que estabelece diferenças entre os sujeitos sociais. A disciplinarização age sobre os indivíduos, transformando-os em agentes do mesmo poder, pela introjeção e racionalização de seus pressupostos.

Diante dos estudos da pedagogia cultural e das investigações sobre os processos culturais contemporâneos, reitera-se a necessidade de que os campos da pedagogia e das licenciaturas abranjam em seus processos formativos a discussão sobre as subjetividades e o trato dos valores contemporâneos na escola atual, considerando a hibridação das diversas identidades, de gênero, raça, etnias, entre tantas origens culturais dos estudantes.

Nessa perspectiva, Guattari (1999) referiu-se a processos que podem, de outra perspectiva, subjetivar a sensibilidade dos jovens, ao desterritorializar códigos dominantes na sua formação. Os interesses, os desejos e as motivações dos adolescentes podem ser canalizados em experiências que se relacionem aos seus interesses, mas também aos interesses de grupos e causas sociais e culturais afirmativas. Para Foucault (2004), nos encontros entre os indivíduos ocorre o confronto de visões de mundo, que tendem a ampliar as percepções individuais e levam a analisar as questões relativas ao "outro" social. 
Foucault (1995) contribui de maneira significativa com relação à reflexão sobre a ética ao concebê-la como forma de relacionamento do indivíduo para "consigo mesmo" e com "os outros", isto é, relacionada às opções que precisa fazer por ações morais e éticas, o que supõe aceitar a variabilidade de atitudes e a diversidade a que está exposto na vida social, cultural e nas relações humanas. Ao considerar a própria vida uma obra de arte, Foucault propõe a formação de uma ética pessoal, contingente, na qual a escolha é possível, mas tendo como condição a consciência sobre os jogos de verdade e de poder na sociedade.

A escola é lugar social e, por isso mesmo, de experiências, de discussões e de encontros que acontecem de forma natural, mas que podem também ser oportunizados. As discussões sobre as notícias e programações da TV podem e precisam ser abertas a partir de elementos que auxiliem o entendimento dos jovens e das comunidades sobre direitos humanos e sociais e outras questões que reafirmem suas opções éticas e suas singularidades. Cabe identificar nas práticas pesquisadas as possibilidades que se abrem a essas perspectivas e em função da formulação que norteia as análises propostas na pesquisa.

\section{OS PROCESSOS DAS PRÁTICAS DOCENTES CATALISADORAS: ELEMENTOS PARA A ANÁLISE}

A investigação proposta refere-se às formas como os professores catalisadores tratam os novos interesses e valores dos estudantes de escolas públicas, uma vez que, ao refletir e constatar os novos processos culturais que decorrem das mudanças contemporâneas, retomam concepções, valores e práticas que adquiriram nos processos de formação e em suas trajetórias profissionais.

Entre os vários autores que se dedicaram à pesquisa sobre formação e práticas dos professores, optou-se por buscar elementos para a presente investigação nas contribuições de Lee Shulman (1987), autor que se dedicou à análise dos processos que os professores desenvolvem ao ensinar/formar seus alunos. Nesses processos, os docentes mobilizam várias formas de conhecimentos relativos ao conteúdo específico de área de ensino, do currículo, do contexto (macro e microssocial) e dos alunos e suas características. Destaca, ainda, os conhecimentos dos contextos educacionais, que envolvem tanto a sala de aula e os ambientes de trabalho pedagógico quanto as comunidades, as culturas, etc. como formas de interação com os alunos, e estes são aspectos que têm sido observados nas pesquisas sobre os professores catalisadores.

Os procedimentos dos professores não serão analisados de forma linear, sendo que o foco de análise na pesquisa realizada refere-se aos processos desenvolvidos ao tratar situações que incluam os valores dos estudantes decorrentes das mídias digitais, levando em conta novos temas, novas atividades, preocupações e opiniões, procedimentos que levam a modificar formas de agir e pensar e que construam o que Shulman (1987) qualifica como nova compreensão. Nesta perspectiva, nas mediações de suas práticas, os professores constroem constantemente seus conhecimentos e procedimentos pedagógicos e os amalgamam a outros tipos de temas e contextos, dando origem a outros e/ou novos conhecimentos e compreensões.

A ideia de um amálgama aproxima-se da definição de catálise, no sentido de que nesses dois processos aglutinadores são elaborados projetos ou planos de trabalho, selecionando as representações mais úteis de uma dada noção a ser ensinada, analogias, ilustrações, exemplos e explanações, informações e novos materiais que se incluem nas condutas que circulam na comunidade e/ou nas culturas dos estudantes, levando aos propósitos da formação pretendida (SHULMAN, 1986, p. 9).

Nesse processo, levam em conta os repertórios e culturas que os estudantes trazem para as situações de aprendizagem. A compreensão é utilizada por Shulman (1986) como elemento-chave de análise, no qual caracteriza as formas de ensinar/formar. Refere-se ainda Shulman (1986) à verbalização dos professores sobre os processos que desenvolvem, nos quais exercem um domínio epistemológico sobre seus próprios conhecimentos e experiências, que incluem as culturas e pré-conhecimentos dos estudantes. Essas categorias compreensão, verbalização e nova compreensão - foram levadas em conta para identificar a busca de possibilidades de articulação entre as culturas dos estudantes e os valores humano-sociais (éticos, de direitos humanos e igualdade social e cultural e outros que surgissem nas situações pesquisadas).

A análise das práticas pesquisadas considerou os aspectos culturais e sociais contemporâneos e o reconhecimento de processos de subjetivação na cultura das mídias digitais e das relações de poder e saber/ poder nas relações escolares, considerando a formação dos estudantes para escolhas éticas na sociedade. Levase em conta o apoio teórico de Foucault $(1995 ; 2004)$ e Guattari (1987; 1999), bem como de outros autores que contribuíram teoricamente com as questões formuladas na pesquisa.

\section{OS SUJEITOS DA PESQUISA E OS PROCEDIMENTOS METODOLÓGICOS}

Os seis professores que participaram da pesquisa foram selecionados por apresentarem em suas práticas 
características que os situam como representativos de professores catalisadores pesquisados no período de 2009 a 2012 e desenvolvem a docência em escolas públicas estaduais e municipais de Curitiba. As pesquisadoras, bolsistas de Iniciação Científica, desenvolveram projetos sobre o tema em pauta, tendo participado de discussões durante o processo de estudo, análise dos depoimentos e observação das atividades, discutidos com as supervisoras dos projetos.

Os(as) professores(as) pesquisados(as) são graduados(as) nas áreas de ensino de Língua Portuguesa, Inglês, Ciências, História e Geografia, com cursos de especialização ou mestrado nas respectivas áreas em que atuam ou em outra área, e dois professores ministram aulas em duas áreas de ensino. $O$ tempo de atuação na função docente variou de 5 a 18 anos, o que levou a constatar que as práticas e atitudes catalisadoras nem sempre estão atreladas ao maior ou menor tempo de serviço.

As áreas de ensino foram diferenciadas, sendo que o foco central da pesquisa concentrou-se nos processos pedagógicos, nos quais empregam novas visões e compreensões, que caracterizam o trabalho de catálise desenvolvido, independente da área de ensino em que se realizou a pesquisa.

A pesquisa, de cunho qualitativo, foi realizada com base nos procedimentos de Lüdke e André (1986) e iniciou com a aplicação de um questionário semiestruturado, do qual foram destacadas três questões que pudessem ser analisadas mais pontualmente na presente abordagem, considerando as compreensões e possíveis influências das práticas catalisadoras no trato dos valores dos estudantes: a opinião sobre os alunos de hoje; as preocupações com a formação de valores dos estudantes diante de sua inserção nos processos das mídias digitais; a verbalização sobre os movimentos da prática observada, que podem ser atividades ou procedimentos, ao tratar os valores dos estudantes gerados pelas mídias digitais.

Após a aplicação do questionário, foi previsto um retorno dos professores, realizado em reunião posterior. Houve oportunidade, então, de ampliação e aprofundamento de respostas ao questionário aplicado, clarificando temas abordados, opiniões, concepções e mobilização de conhecimentos, entre outros aspectos que surgiram nos processos pesquisados. Na sistematização das duas primeiras questões, buscou-se não identificar por nomes os professores e aproximar opiniões similares e também posições representativas dos depoimentos dos professores.

Na terceira questão foi proposta a observação de uma aula ou procedimentos de uma atividade, previamente programados com os professores pelas bolsistas. Nas análises das atividades de sala de aula com as pesquisadoras, as bolsistas participantes participaram das análises comentando os temas trabalhados e os pontos significativos das atividades, à luz dos autores consultados, sistematizados em relatório final.

O tempo de pesquisa com cada professor, para as observações em sala de aula e entrevistas ou aplicação do questionário, foi de dois meses, por vezes ultrapassado. ${ }^{6}$ Ao final, foram identificadas questões, assuntos e procedimentos que contemplaram os interesses e valores dos estudantes e as possibilidades surgidas de articulações com os valores humano-sociais, identificando aspectos que respondessem à formulação inicial.

\section{OS VALORES GERADOS PELAS CULTURAS DIGITAIS: POSSIBILIDADES DE ARTICULAÇÕES AOS VALORES HUMANO- SOCIAIS NAS PRÁTICAS PESQUISADAS}

Nas duas primeiras questões, relativas à opinião dos professores sobre os alunos de hoje e à influência das mídias digitais, quase todos comentaram sobre a complexificação da função docente diante dos outros interesses e espaços da sociedade contemporânea. Observaram que boa parte dos alunos tem na escola um espaço social; preocupam-se com a falta de discussões sobre os sujeitos da escola diante da proliferação dos aparatos da mídia digital, coadjuvantes, de certa forma, do trabalho da escola, mas nunca discutidos pelos coletivos de professores ou equipes pedagógicas.

Comentaram sobre as novas formas de ser, estar, "ficar", se relacionar entre colegas, na sociedade atual, e observavam a atração dos jovens por pertencer a grupos diversos, desde bares, gangues, jogos eletrônicos, discotecas tecno, etc., nos quais sentem-se aceitos, "enturmados".

Com relação às influências das mídias digitais nas culturas dos estudantes, os(as) professores(as) comentaram que reconhecem a grande evolução dos meios de comunicação tecnológica, cinematográfica, das redes sociais nos circuitos da internet e do uso de outros instrumentos digitais, que têm conotações de ampliação do conhecimentos nas várias áreas e nos relacionamentos entre colegas jovens. Por outro lado, os professores comentaram que essas programações funcionam como lazer virtual, monopolizando desejos, modos de ser, atuando no imaginário dos adolescentes, formando opiniões e subjetividades.

Ressaltaram que a TV ainda é o artefato da mídia de maior inserção na vida dos estudantes da escola pública, e sua interferência é significativa em suas identidades e valores. Comentou uma das professoras: "As novelas, programações e noticiários da televisão ditam comportamentos, formas de vestir, nem sempre possíveis aos jovens, naturalizam a violência, a frustração 
e o enriquecimento desonesto, e quase não se veem esclarecimentos sobre assuntos de interesses dos jovens".

Sobre o papel do professor nas influências e mudanças que observam nas identidades e valores dos estudantes, algumas posições constataram a necessidade de retomar o que pensam sobre seu papel no âmbito escolar atual. Afirmou uma das professoras que "é necessário que nos aproximemos dos alunos, ao invés de querer que eles se adaptem a nós, ao que pensamos. Eu procuro várias formas para que cheguem aos conhecimentos que serão necessários em sua vida, e que precisam ter". Propôs que educadores e professores discutam as questões relativas aos seus papéis, de forma sistemática, e complementou: "[...] porque as mudanças que presenciamos são rápidas no mundo atual, e nem sempre acompanhadas pelos cursos de formação e pela escola".

Com relação à evolução tecnológica e das mídias digitais, falaram sobre a necessidade de dominar assuntos e novos temas para os quais não foram formados, diante de tantas mudanças e da cultura digital. Para um dos professores, "os instrumentos da mídia são também pontes entre as atividades desenvolvidas e os alunos, mas precisamos voltar aos cursos e leituras sobre tecnologias, sociologia, antropologia, educação ambiental, para dar conta das necessidades dos alunos".

$\mathrm{Na}$ terceira tarefa ou questão, cada bolsista pesquisadora elegeu um dos professores que pesquisou e uma das práticas de sala de aula que observou, na qual identificou o trato do(a) professor(a), ao desenvolver atividades ou procedimentos relativos a valores dos estudantes gerados pelas mídias digitais. A seguir, apresenta-se a sistematização das atividades observadas, considerando cada professor pesquisado, apresentado por sua área e série de atuação, com nomes fictícios.

O professor Lauro, de Língua Portuguesa, de $3^{\circ}$ ano, foi selecionado por uma das pesquisadoras por notícias em sites disponíveis na internet sobre um projeto que manteve para a valorização dos livros de literatura. $\mathrm{O}$ professor e seus alunos selecionavam bons livros de leitura e os deixavam em praças e locais de circulação de pessoas, com uma mensagem de preservação e de passá-los adiante, saindo do bairro da escola para várias outras localidades da cidade de Curitiba.

Essa proposta foi noticiada pela televisão e teve boa repercussão no ano de 2009 entre os alunos, professores e em noticiários locais. Para o professor, a leitura e a literatura são relegadas a um segundo plano nas escolas públicas. O professor manteve um site no YouTube para contatos com outros professores, e a proposta teve um impacto de formação de opinião e instauração da cultura de ler.

Declarou o professor que "é possível perceber a crença na possibilidade de que os estudantes e os indivíduos venham a ser envolvidos, preservem os livros e sejam instigados a ler também". Para o professor, o acesso à leitura de bons livros no projeto tenderia a instaurar a cultura da leitura e da literatura na escola e em outros lugares da cidade e oportunizaria o envolvimento dos alunos no objetivo de propiciar a outras pessoas o interesse de ler. Pensa que não é fácil instaurar a cultura de ler, mas vê que há formas interessantes de levar o aluno a ler e a não pensar neste momento em consumir, porque os livros são doados pela comunidade em geral, e há uma seleção posterior dos que serão lidos. Segundo o professor, é o exercício de viver sem somente consumir.

Para o professor, os valores surgem de experiências reais e, nessa perspectiva, Bondía (2002, p. 8) alertou para a noção de sensibilização sobre uma determinada experiência e o tempo para que aconteça, que permita parar para pensar, olhar, escutar, sentir, demorar-se nos detalhes, emitir opiniões, cultivar a atenção, abrir os olhos e os ouvidos e falar sobre o que aconteceu. Percebeu-se, neste caso, que o uso que o professor fez de várias mídias e a divulgação do projeto por um meio de comunicação das mídias digitais levaram seus alunos também a instigar "outras pessoas" a ler livros de literatura.

A professora Marisa, do $6^{\circ}$ ano, da área de Ciências, foi selecionada por buscar formas de resolver em sua sala de aula o uso dos celulares. Comentou que discutia com seus pares a atitude dos alunos ao usar o celular em sala de aula. Declarou a professora que, apesar disso, observava que "os celulares fazem parte da vida na sociedade e, por isso, também dos jovens. Por esse motivo resolvi adotá-los em visitas que promovo a museus, para discutir assuntos das aulas de Ciências". Relatou a professora sua proposta de realização de relatórios sucintos sobre as visitas a museus ou a outros locais, para motivar seus alunos a utilizar os celulares nessas atividades. Propôs uma retomada das anotações sobre o tema em sala de aula e que os alunos elaborassem textos individuais e/ou coletivos sobre os conceitos discutidos.

Oportunizou ainda um diálogo sobre os celulares em sala de aula, o que resultou na discussão da função do professor e dos alunos na escola, o que implica tempo de atenção, trabalho e concentração. "Nessa discussão eu me coloquei junto com os alunos, que passaram a pensar nas possibilidades de uso de celulares de forma que todos pudessem exercer esse direito, pensando nas atividades de cada um".

A professora ofereceu oportunidade de discutir sobre o tema, que é polêmico e relacionado às necessidades e hábitos dos jovens, o que possibilitou a circulação do poder na sala de aula, diminuindo a distância entre a professora e os estudantes.

O professor Gabriel, de Língua Portuguesa, da $8^{\mathrm{a}}$ série de uma escola pública, convidou a pesquisadora 
para assistir às suas atividades, geradas por comentários frequentes dos alunos sobre os problemas da cantora Amy Winehouse, que finalizou uma carreira brilhante em 2011 e foi alvo de comentários negativos na imprensa.

Passou a pesquisar textos que exploravam os diversos pontos de vista de informações sobre a cantora e solicitou aos alunos uma pesquisa semelhante. Segundo o professor: "Tratar de um ícone ou personagem admirado pelos(as) jovens levou a mostrar comentários de preconceito, rotulações e julgamentos à cantora. Os(as) alunos(as) incorriam em comentários negativos, entre outros, que levaram o professor a explicar o que causa 'danos morais' a alguém".

Recorreu a vários textos jornalísticos, como o depoimento de um ex-viciado, as histórias e críticas sobre os porquês de condutas destrutivas em pessoas jovens e de grande projeção, o depoimento do delegado que acompanhou o caso de Amy, as declarações de uma amiga e de uma ex-fã da cantora, agredidas em lugares frequentados por ela. Os diálogos sobre os textos e programas de TV que exploraram o tema ofereceram condições aos estudantes de analisar não só o fato em si, mas questões de interesses pessoais, utilizando vários tipos de textos.

Em movimento contrário aos códigos da sociedade globalizada quanto a julgamentos inconsequentes sobre "o outro", o professor levou aos alunos argumentos sobre os direitos "desse outro", buscando mobilizar opiniões e opções por formas éticas de analisar a situação da cantora. Para Foucault (2004), trata-se de colocar o indivíduo diante de opções que impliquem revelar os "jogos de verdade" da sociedade e que possibilitem escolhas éticas pessoais. As atividades vividas pelos alunos tornaramse oportunidade de resistência e discussão da opressão cultural e social, em todas as suas formas.

A professora Rosana, de uma escola estadual, é formada em Letras e atua em aulas de Inglês e de Língua Portuguesa. É graduada também em Artes e pós-graduada em Literatura, Leitura e Produção Textual, possuindo ainda especialização em Teatro. Foi selecionada pela divulgação de seu trabalho diferenciado pela internet, por meio de vídeos postados no site da escola em que trabalha.

A professora confeccionou um vídeo artístico que desenvolveu com os alunos ao montar a peça de teatro Sonhos de uma noite de verão, de William Shakespeare. Comentou sua proposta de trabalho, que desenvolveu para melhorar o vocabulário de inglês dos alunos. Comentou que desenvolveu um vídeo com seus alunos de Artes sobre o tema "Sertanejo universitário", para discutir as origens dessa modalidade de música e as suas implicações para a música brasileira.

A professora destacou seu interesse por novas metodologias de ensino: "Na matéria que leciono, Língua
Inglesa, gosto de inovar; trabalho com seminários, com textos em inglês para aquisição de vocabulário, jogos de perguntas e Quiz, que levam a respostas que não aparecem nos conteúdos das propostas da área e despertam a curiosidade dos alunos".

Os temas bastante atuais desenvolvidos pela professora e a experiência de elaboração de um vídeo foram também o início de um interesse que constituiu um processo de formação dos alunos sobre os temas explorados. Segundo Shulman (1987), este procedimento torna-se um amálgama de vários conhecimentos, informações e recursos, que tende a catalisar destrezas e opiniões dos alunos sobre o desenvolvimento de um assunto ou tema de seu interesse.

Como alertaram Green e Bigun (2005), o domínio requisitado aos professores sobre as mídias digitais não é só relativo aos conhecimentos tecnológicos e seu uso, mas diz respeito à maior aproximação dos adultos dos interesses, destrezas e valores dos jovens. No movimento de mediação promovido pelos professores, observa-se que o ponto de partida em várias ocasiões é de temas que os jovens conhecem, valorizam e dominam, como pontes para as aprendizagens de conhecimentos eruditos e outros que precisam adquirir na escolarização.

A professora Cely, da $3^{\text {a }}$ série do Ensino Fundamental, comentou que utiliza nomes de heróis em suas aulas com alunos de $2^{\circ}$ ano. Refere-se à convivência dos alunos com personagens, heróis e ícones que conhecem e aprovam nas programações midiáticas. Suas preocupações, no entanto, voltam-se à violência veiculada em boa parte dos filmes, vídeos e games, nos quais os heróis têm uma atuação de conotação lúdica, mas que, no entanto, trazem a marca da violência e do extermínio.

As constatações sobre essa circulação da violência como notícia e de várias formas têm levado a professora a planejar situações nas quais os alunos possam retomar as histórias, discutir as atitudes dos seus protagonistas, mas não com o intuito de modificar ou forçar opiniões. Propõe a reprodução das histórias contadas pelos alunos e seus heróis em desenhos, cartazes e textos, retomando atitudes. Afirmou a professora: "Não temos outra saída que não seja o diálogo sobre o que os alunos assistem, seus heróis e histórias que têm para contar, o que querem dizer. Só assim se dialoga sobre os porquês da violência presenciada por todos de forma aberta".

Questionada sobre a influência dessas atividades na formação dos alunos, declarou que "[...] não se pode ainda avaliar tais atividades como influências nos valores dos alunos, mas acredito que o espaço para essas discussões, com reflexões frequentes e a médio prazo, de forma sistemática, pelos professores nas escolas teria um efeito de esclarecimento para a formação de valores". 
A professora Carol, de Geografia, de escola pública, é formada e tem especialização em sua área de ensino. Tem turmas do $7^{\circ}$ ano e procura utilizar vídeos e filmes em suas aulas, fazendo uso da mídia para a pesquisa sobre temas de Geografia e outras áreas. Nas aulas observadas, utilizou a internet e falou sobre a veiculação de informações variadas, que precisa ter critérios para selecionar o que será trabalhado com os alunos.

A professora procura esclarecer as programações comentadas pelos alunos e realiza um movimento de desconstrução de generalizações de conceitos sobre questões sociais relacionadas à área de Geografia, com discussões e trabalhos de grupo. Exemplificou outras situações como "invasão de propriedade", movimentos sociais como o dos "sem-terra" e os porquês do ativismo, tendo exemplificado com as atividades do Greenpeace. $\mathrm{O}$ interesse da professora por grupos de afirmação social a levou a propor atividades de pesquisa sobre esses temas e movimentos. Para a professora, "o homem contemporâneo é formado pela escola também; não é mais possível educar sem falar do papel de cada um no mundo em que se vive".

Para Guattari (1987), os processos de subjetivação promovidos pelas programações das mídias digitais promovem a homogeneização de opiniões. Captar os interesses, os desejos e as motivações dos jovens em atividades, pela promoção de encontros com eles ou outras pessoas que se voltam aos problemas ambientais, aproxima os estudantes das diversas e outras visões e tende a canalizar desejos e possibilidades dos jovens para experiências próprias sociais e culturais.

A atitude de compreensão sobre o próprio papel ao fazer escolhas para desenvolver suas atividades, tanto no planejamento quanto nas práticas cotidianas, leva o professor a transformar os processos de ensino, segundo Shulman (1987). Na formação de valores, observouse que as preocupações dos professores trouxeram a necessidade de discutir e dialogar sobre atitudes e valores humano-sociais, sobre temas e atitudes de seu interesse aplicáveis à sua vida e que os preocupam, considerando os processos de massificação e homogeneização de opiniões, oportunizando experiências na vida cotidiana dos estudantes.

\section{DiMENSões CONCLUSIVAS}

A entrada da cultura contemporânea na escola básica e os processos enfrentados pelos professores na constituição dos sujeitos que a frequentam, diante da complexa questão dos valores gerados pela cultura das mídias digitais, foram analisados nas possibilidades e flashes da sistematização sobre a pesquisa realizada. Os aspectos valorativos identificados para a busca de novas formas de conduzir as práticas dos professores catalisadores partiram dos próprios estudantes (comentários, notícias da mídia, uso dos celulares, etc.), e as possibilidades de articulações promovidas considerando valores humanosociais, sob novas perspectivas, apareceram como ensaios de novas formas de conviver com a cultura jovem.

As preocupações sobre temas relativos a equívocos, preconceitos, violência, oportunizaram discussões e análises que propiciaram experiências coletivas e individuais sobre questões contundentes, envolvendo novas visões e interesses que circulam entre os estudantes. Constituíram uma lição de verdade sobre o que realmente se verifica no cotidiano dos jovens das escolas públicas.

$\mathrm{O}$ professor que desenvolveu as atividades sobre o caso da cantora Amy Winehouse talvez tenha congregado um maior número de atividades qualitativas, que permitiram aos alunos olhar para si mesmos, para os preconceitos, dando ensejo a discussões sobre "jogos de verdade" da sociedade atual, ensejando aos estudantes, comparações com situações que enfrentam como jovens. Foi possível observar os esclarecimentos necessários para uma ética pela qual se pode optar e que constrói formas mais inclusivas de analisar "o outro". A compreensão e a aceitação do mundo jovem tornaram possível um trabalho sem imposições e que tem propiciado o trânsito de outras e novas lógicas de analisar as situações humanas, o que não exclui a dignidade e o respeito às diferentes formas de ser e se conduzir.

Nas suas práticas, os professores, portanto, evocaram os valores humano-sociais em atividades que requisitaram essa articulação, mas a forma de tratá-los apresentou mudanças significativas. O diferencial das posições e atividades observadas na pesquisa é que noções fundamentais como a ética ou o reconhecimento dos direitos humanos não foram discutidos nas atividades como opiniões maniqueístas com a certeza de verdades irrefutáveis ou regras impostas. Percebeu-se que nas reflexões oportunizadas está mesmo implícita uma nova atitude diante dos significados, opiniões e argumentos dos jovens da escola atual.

Outra questão observada refere-se ao tempo investido nos diálogos e aproximações aos interesses, assuntos, situações-problema dos estudantes. Essas discussões têm sido desenvolvidas em relação a várias possibilidades abertas ao trato da formação dos jovens estudantes e agregam os aparatos das mídias digitais, como a massificação das músicas, as danças jovens, a cultura clássica, que, como se observou, estão conectadas às áreas de ensino, permitindo que se tornem mediadoras para as aquisições da escolarização. Nesse sentido, o tempo parece estar dividido entre as discussões culturais e as áreas de ensino, ou também sendo potencializado em práticas que catalisam os processos pedagógicos em várias experiências e atividades. 
Para boa parte dos professores pesquisados, cabe à escola e aos professores discutir e tomar para si a análise dos temas das programações televisivas, em articulação às opções e escolhas mais conscientes e esclarecidas, que considerem a formação das subjetividades e identidades dos estudantes. Uma das professoras referiu-se ao diálogo cotidiano e a um trabalho pedagógico coletivo dos professores, de forma sistemática.

A pergunta sobre a possibilidade de transitar entre os novos processos culturais dos estudantes em articulação com as áreas de ensino e valores humano-sociais mostrou possibilidades de atividades mais prazerosas para o momento de vida do jovem, como interesses por atividades artísticas, de leitura por prazer, música, como se percebeu nos projetos desenvolvidos.

Reitera-se a necessidade de uma abordagem mais ampla e plurifacetada com relação aos cursos de Pedagogia e das licenciaturas, que contemple as interfaces entre a educação escolar, a escola e a cultura e os sujeitos implicados, os estudantes da escola contemporânea. Requisita-se a retomada nos currículos de formação docente, dos processos valorativos da cultura jovem, sob novas óticas e perspectivas. Os referenciais das atividades dos professores na pesquisa, tiveram esse propósito: de contribuir para novas leituras, lógicas e aproximações dos cursos de formação docente em Pedagogia e demais licenciaturas, relativos aos processos culturais gerados pelas mídias digitais que as estratégias e atitudes dos professores catalisadores tendem a ressignificar.

\section{REFERÊNCIAS}

BAUMAN, Zigmund. Modernidade líquida. Trad. de Plínio Dentzien. Rio de Janeiro: Jorge Zahar, 2001.

BONDÍA, Jorge Larrosa. Notas sobre a experiência e o saber da experiência. Revista Brasileira de Educação, Campinas-SP, n. 19, jan./abr. 2002.

COSTA, Marisa Vorraber e MOMO, Mariangela. Sobre a "conveniência" da escola. Rev. Bras. Educ. [online]. 2009, vol.14, n.42, pp. 521-533. ISSN 1413-2478. Disponível em: <http://dx.doi.org/10.1590/S1413-24782009000300009>.

COSTA, Marisa Vorraber. Quem são? O que querem? O que fazer com eles? Eis que chegam às nossas escolas as crianças e jovens do século XXI. In: MOREIRA, A. F. B.; ALVES, M. P. C.; GARCIA, R. L. Currículo, cotidiano e tecnologias. Araraquara: Junqueira \& Marin, 2006. p. 96-109.

Sobre as contribuições das análises culturais para a formação de professores do início do século XXI. Educar em Revista, Curitiba, Editora UFPR, n. 37, p. 129-152, maio/ago. 2010

DELEUZE, Gilles; GUATTARI, Félix. Mil platôs: capitalismo e esquizofrenia. Trad. de Ana Lúcia de Oliveira e Lúcia Claudia Leão. São Paulo: Editora 34, 1995. v. 2.
FISHER, Rosa Maria Bueno. Mídia e educação: em cena os modos de existência jovem. Educar em Revista, Curitiba, Editora UFPR, n. 26, p. 17-38, 2005.

FOUCAULT, Michel. O sujeito e o poder. In: DREYFUS, H.; Rabinow, P. Michel Foucault - uma trajetória filosófica: para além do estruturalismo e da hermenêutica. Rio de Janeiro: Forense Universitária, 1995. p. 231-249.

Vigiar e punir: nascimento da prisão. 21. ed. Trad. de

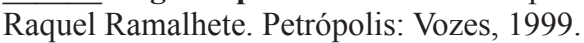

A ética do cuidado de si como prática de liberdade. In: Ditos \& escritos V: ética, sexualidade, política. Tradução de E. Monteiro e I. A. D. Barbosa. Rio de Janeiro: Forense Universitária, 2004.

GIROUX, Henry. O pós-modernismo e o discurso da crítica educacional. In: SILVA, T. T. (Org.). Teoria educacional crítica em tempos pós-modernos. Trad. de Tomaz Tadeu da Silva. Porto Alegre: Artes Médicas, 1993. p. 41-69.

Cruzando as fronteiras do discurso educacional: novas políticas em educação. Trad. de Magda França Lopes. Porto Alegre: Artmed, 1999.

GREEN, Bill; BIGUN, Chris. Alienígenas na sala de aula. In: SILVA, T. T. Alienígenas na sala de aula: uma introdução aos estudos culturais. Petrópolis: Vozes, 2005. p. 133-158. (Col. Estudos Culturais)

HAGEMEYER, Regina Cely de Campos. Função docente e contemporaneidade: fundamentando o processo das práticas catalisadoras. Tese de doutorado defendida na Universidade de São Paulo, 2006.

GUATTARI, F. Revolução molecular. São Paulo: Brasiliense, 1987.

Da produção de subjetividade. In: PARENTE, A. (Org.). Imagem máquina: a era das tecnologias do virtual. Rio de Janeiro: Editora 34, 1999. p. 177-191.

HALL, Stuart. A centralidade da cultura: notas sobre as revoluções culturais do nosso tempo. Educação \& Realidade, v. 22, n. 2, jul./dez. 1997.

JAMESON, Frederic. Pós-modernismo: a lógica cultural do capitalismo tardio. Tradução de Maria Elisa Cevaso. São Paulo: Ática, 1996.

LYOTARD, Jean François. The post modern condition Minneapolis: University of California Press, 1998.

LÜDKE, Menga; ANDRÉ, Marly Dalmazo A. Pesquisa em educação: abordagens qualitativas. São Paulo: EPU, 1986.

RAMOS DO Ó, Jorge; COSTA, Marisa Vorraber. Desafios à escola contemporânea: um diálogo. Educação \& Realidade, v. 32, n. 2, p. 109-116, jul./dez. 2007.

SHULMAN, L. S. Those who understand: knowledge growth. Teaching Educational Researcher, v. 15, n. 2, p. 4-14, 1986.

Knowledge and teaching: foundations of the new reform. Harvard Educational Review, v. 57, n. 1, p. 1-22, 1987.

SANTAELLA, L. Culturas e artes do pós-humano: da cultura das mídias à cibercultura. São Paulo: Paulus, 2003.

WILLIAMS, Raymond. Cultura e Sociedade. Tradução de: HEGENBERG, Leônidas; MOTA, Octanny Silveira da; TEIXEIRA, Anísio. São Paulo: Companhia Editora Nacional, 1969. 


\section{Notas}

${ }^{1}$ Entre autores que têm trabalhado com o tema cultura das mídias, Santaella (2003) esclarecea expressão“cultura das mídias digitais”, queé utilizada no plural, como cultura que nasce nos trânsitos, intercâmbios e misturas entre os diferentes meios de comunicação digitais e não digitais. Nessa abordagem, e priorizam-se os processos culturais gerados pelas mídias digitais, que não excluem os intercâmbios das mídias não digitais.

${ }^{2}$ Os projetos foram desenvolvidos por quatro pesquisadoras, alunas de Pedagogia.A Iniciação Científica é desenvolvida pela Pró-Reitoria de Pesquisa e Pós-Graduação (PRPPG) da Universidade Federal do Paraná (UFPR), sob a orientação das autoras deste artigo.

3 Título da tese: Função dos professores na contemporaneidade: fundamentando os processos das práticas catalisadoras, tese de doutorado defendida na Universidade de São Paulo em 2006.
4 A pós-modernidade, a partir da periodização de historiadores e intelectuais como Williams (1969),Jameson(1996), Giroux (1993),Lyotard (1998) e Bauman(2001)inicia emmeados do século XX, sendo que alguns autoresprecisamessa mudança no ano de 1960.

5 Desde 1993,Giroux vem estabelecendo diálogos com autores da cultura pós-moderna, predominantemente midiática, considerando problematizações e pesquisas sobre áreas pedagógicas em locais ou meios que difundem e organizama cultura e o poder,como TV, cinemas, jornais, brinquedos, propagandas, videogames, livros, etc.

${ }^{6}$ Os relatos serão descritos indicando o professor que o proferiu, observando que os nomes são fictícios.

Artigo recebido em setembro 2013

Aprovado em dezembro 2013. 